\title{
Kanji Learning by FL Students from Character and Non-character Based Language Backgrounds - Report from a Foreign Language Class
}

\author{
Sayuki Machida \\ University of Melbourne, Australia
}

\begin{abstract}
This is classroom-based action research to develop a subject syllabus. The subject aims to improve the kanji learning of learners from both character (CB) and non-character based (NCB) language backgrounds. This paper reports the first phase of a three year long project to develop the proposed subject. It investigates the performance of $\mathrm{CB}$ and NCB learners at the beginning and end of a pilot course of the subject. The objectives of the study is to obtain a broad picture of the CB and NCB speaker groups' kanji performance in order to locate possible areas of difficulty for the further examination. The findings indicate advantages of a character based language background for learning kanji. However, the two groups did not show much difference in reading kanji which had been formally introduced in class. Neither group could easily correct kanji reading or writing errors by themselves.
\end{abstract}

Index Terms - Japanese written system, kanji learning, character background, non-character background

\section{INTRODUCTION}

Kanji learning does not seem to be an easy task at all. Even in Japan, where kanji are part of the mother tongue's written system, there has been a constant effort to keep the number of kanji under control. Joyo-Kanji, literally Kanji for Common Use, is designed to "serve as a yardstick so that her public media uses a limited number of kanji more effectively to facilitate day-to-day communication among her people" (Encyclopaedia Britannica's Japanese International Dictionary). The list of Joyo-Kanji has been published since 1923 (e.g., Sato, 1989; Tamaoka, 1991; Wikipedia: Joyo-Kanjil ${ }^{I}$ ), when they were first set by the Ministry of Education (文部省臨時国語調査会 ${ }^{2}$ ). They were reduced to 1,856 characters in 1931. The number was increased to 1,945 in 1981, and the Cultural Advisory Committee (文化審議会) further increased them to 2,136 in 2010. In the process, some old kanji ${ }^{3}$ used with the old kana-zukai (old hiragana written system) were officially simplified (mostly because these complex characters had been largely replaced by their abbreviations in everyday usage) (Sato, 1989).

China, from which Japanese adopted kanji into the Japanese written system, also simplified their characters for common use. Since 1956, simplified characters were introduced several times (i.e., 1959, 1977, 1980, and 1986). Characters were simplified in many ways, but mainly by reducing the overall number of characters and the number of strokes per character (Ingulsrud \& Allen, 1999).

If kanji are not easy for native speakers, how hard is it for non-native speakers, especially speakers of alphabetic languages? This is the starting point of this classroom-based research. In Japanese as a foreign language (JFL) class, a common belief among teachers and learners is that Kanji learning is notoriously hard for speakers of non-character based (NCB) languages and is not as easy for character based (CB) language speakers as it appears. The JFL teachers observe that although CB speakers sometimes outperform NCB speakers, sometimes they underperform them. This paper investigates how students from $\mathrm{CB}$ and NCB backgrounds progressed in the same tertiary JFL course where the focus is on kanji learning.

\section{BACKGROUND}

\section{A. Literature Review}

Kanji are a large part of Japanese vocabulary and particularly of content words, such as nouns, verbs, adverbs, etc. Thus kanji knowledge and comprehension is very important for word recognition in Japanese. Research findings suggest there are possibly different models of word recognition by the speakers of an alphabetic language (English) and a logographic language (Chinese).

The Interactive-Activation Model (McClelland \& Rumelhart,1981) originally developed for the English language system has been modified to explain recognition of Chinese character words (Taft, Liu \& Zhu, 1999). The model

\footnotetext{
${ }^{1}$ http://ja.wikipedia.org/wiki/\%E5\%B8\%B8\%E7\%94\%A8\%E6\%BC\%A2\%E5\%AD\%97

${ }^{2}$ Special Committee on National Language organised by the Ministry of Education

${ }^{3}$ The number appears to vary from 254 to 274 .
} 
includes orthographic, phonological and meaning/semantic units which interact with each other. In the orthographic units, visual input is processed at three levels to be recognised as a word, i.e., feature, letter, and word levels. Alphabetical orthographic features such as $\backslash, \mid, \mathrm{c},--$, correspond to the character strokes of a logographic language. The letter level of English language corresponds to radicals (part of characters) to whole single characters (morphemes) of Chinese language, which eventually form words.

Taft, Liu \& Zhu (1999) add abstract units "lemmas" (Levelt, 1989) as the interface for the interaction between orthographic and semantic or phonological units in Chinese word recognition. The abstract units contain the same semantic information repeatedly reoccurring with the same form. Thus the units accumulate a correlation between form and meaning over time. This allows the model to explain how the correct meaning of single characters with multiple meanings can be activated in the comprehension of compound words. (Figure 1)

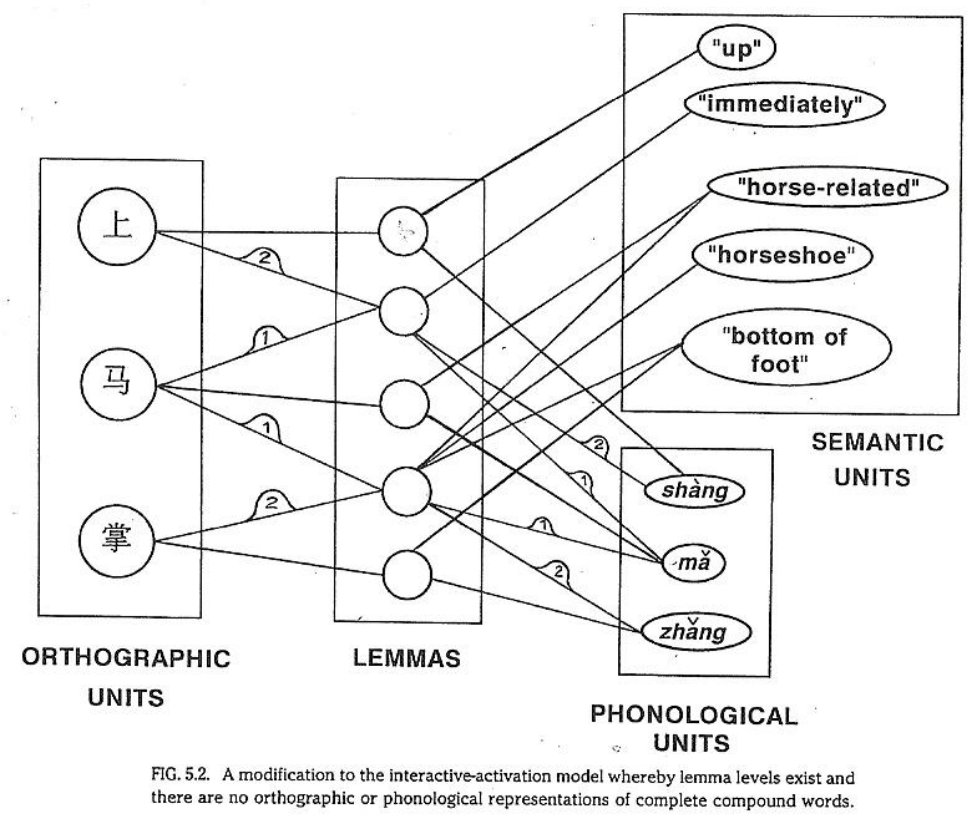

Figure 1 Interactive-activation model for Chinese From Wang, Inhoff, \& Chen, (1999, p.107)

Access to word meaning is essential not only for word recognition but also for comprehension of larger linguistic units, such as sentence, paragraph, etc. Word meaning can be directly accessed visually (orthography to meaning) and indirectly via a phonological path. Kanji words normally consist of a single character plus okuri-gana (hiragana) to make verbs, adjectives, and adverbs (e.g., 食べる、静かな、急いで). Characters are often compounded to make nouns (e.g., 食事、歓迎、休暇).

Compound kanji words can be processed in the same way as Chinese words, using both semantic and phonological access. Zhou et al (1999) argue that direct meaning access from orthographic units is predominant. In their view, the orthographic, phonological and semantic units are not all interactive with each other. Only the orthographic and semantic units interact, and the phonological units are mainly activated after the other two units.

\section{B. JFL Course Structures in General}

JFL courses at tertiary level normally offer content which promotes a balanced four skill development - dividing the course into components each of which focuses either on one skill or on some combination of the four skills (such as listening and speaking, reading and writing, listening and reading, reading and speaking, writing and speaking, etc). Kanji learning (recognition, comprehension in text and use in writing) tends to fall within areas such as script recognition, comprehension of text and writing. A relatively small portion of the course hours is normally allocated directly to kanji learning.

History and derivation of kanji are normally introduced to students during beginner's courses. Once students have learned around 200-250 single characters, they might be introduced to kanji's internal structure: radicals (hen, tsukuri). They may also learn some compounds such as kango words, 食事する (shokuji-suru: to eat) as well as their Wago counter part, 食べる (taberu: to eat), and four character words such as 前代未聞 (zendai-minon: unparalleled). Most of the class hours allocated to kanji learning are spent on explanation of kanji and kanji related matters (such as internal structure, meaning, pronunciation of kanji, and vocabulary including the kanji), or testing students' kanji learning. Very little time is left for students to practice kanji in class, and a large part of kanji learning is left to students' self-study.

\section{Principle behind the Course Syllabus}


It came to our notice that kanji were not- yet-taught or practised systematically after their initial introduction at the beginning of the course, and tended to be introduced and practised simply in relation to the topic in each lesson. Thus, if we deliver a subject which provides 1) an overview of kanji script, 2) explanation of kanji structures, and 3) practice to assist the learners to develop kanji learning strategies, it should promote the students' kanji acquisition. In practice, we need to teach character background (CB) and non-character background (NCB) learners not only in the same course but also in the same class. Therefore we need to develop a kanji subject which caters to both groups.

This study reports the first phase of a three year long project to develop such a kanji subject course. The study aims to obtain a broad picture of what each group's kanji performance was like at the beginning and end of a pilot course of the subject, in order to identify possible areas of difficulty for each or both CB and NCB learners. The picture should also assist with the selection of subject content better adapted to the kanji learning needs of both/each group.

\section{THE STUDY}

\section{A. The Subject Course and Cohort}

The subject course in this study was offered to intermediate learners of Japanese co-currently with their core subject (Level 3 Japanese) which includes practice of the four language skills. The new course presents students with a summary of the current Japanese writing systems, and provides practice to develop kanji learning strategies and opportunities to see kanji from a logographic perspective. The course also intends to promote autonomous learning and voluntary vocabulary building among the learners besides their kanji learning.

The student cohort consisted of $22 \mathrm{CB}$ and 31 NCB speakers. Among them, $13 \mathrm{CB}$ and 23 NCB speakers participated in this study. The course ran for 12 weeks and the class consisted of one hour lecture and 1.5 hour tutorial per week. The lectures presented an overview of kanji script as part of the Japanese writing system and explanation of kanji structures. The tutorials provided exercises intended to assist the learners to develop kanji learning strategies.

Refer to Table 1 for lecture and tutorial topics. The tutorials provided exercises related to each week's topic. The worksheets used in tutorials were a mixture of lecture materials and pages from Basic Kanji Books (Kano et al 1989).

The students were also required to undertake an independent kanji project (20\% of the course assessment). The aim of the project was to improve their kanji learning and build vocabulary. They were expected to discover their best personal methods for remembering kanji as well as utilising the strategies they learned in class. The ultimate goal of the project was mastery of 'kanji on the list'. These kanji were a) previously-taught kanji taught (target kanji in Levels 1 and 2) and b) target kanji for Level 3. Due to individual differences (such as CB or NCB background, how much each student had learned kanji before taking this course, etc), students were instructed to determine their own specific goals. Some students decided their goals were less than complete mastery of the 'kanji on the list', and some set more ambitious goals.

TABLE 1

THE COURSE OUTLINE

\begin{tabular}{|l|l|l|}
\hline Weeks & Lecture & Tutorial \\
\hline Week 1 & $\begin{array}{l}\text { Introduction: Explanation of course objectives, activities and } \\
\text { assessments }\end{array}$ & $\begin{array}{l}\text { Kanji Quiz } \\
\text { Revision of leant } \text { kanji }\end{array}$ \\
\hline Week 2 & History of Japanese writing systems & $\begin{array}{l}\text { Reading exercise } \\
\text { Revision of Japanese writing systems }\end{array}$ \\
\hline Week 3 & Hiragana and katakana (Japanese kana writing systems) & Reading and writing exercises katakana words \\
\hline Week 4 & Japanese sound system and phonetics (vowels, mora, etc) & Revision of the learnt homophones \\
\hline Week 5 & Structures of Japanese words & Practice of radicals \\
\hline Week 6 & Kanji On and Kun reading & Exercises with On and Kun reading and use \\
\hline Week 7 & Structures of kanji & Exercises with kanji structures \\
\hline Week 8 & Compounding kanji & Learning kanji compound characteristics \\
\hline Week 9 & Kanji compound use in sentence & Exercise with kanji compounds, adjectives, affixes \\
\hline Week 10 & Homophones & $\begin{array}{l}\text { Learn homophones and accent } \\
\text { Antonyms, Verbs }\end{array}$ \\
\hline Week 11 & Revision: recognizing kanji words & $\begin{array}{l}\text { Kanji recognition exercises } \\
\text { Presentation of } \text { kanji project }\end{array}$ \\
\hline Week 12 & Summary: how to learn and remember kanji & $\begin{array}{l}\text { Discussion } \\
\text { Presentation of } \text { kanji project }\end{array}$ \\
\hline
\end{tabular}

\section{B. The Purpose of the Study}

This is the first phase of a larger project which ultimately aims to discover more effective ways to teach kanji to a mixed student cohort of CB and NCB speakers. The project seeks approach(es) to motivate both groups, improve their kanji learning and a set of assessments which enables evaluation of their learning through the course. The immediate purpose of the current study is to examine the differences between the CB and NCB speaker groups in terms of kanji learning, particularly regarding:

1. How well CB learners adjusted to kanji learning compared to NCB learners in the same level Japanese language class, 
2. Each group's test performance at the beginning and end of the course, and

3. Fundamental differences in kanji learning between the groups.

\section{The Methods}

To find out the differences between the two groups, the outcomes of two tests were examined and analysed. The first test was given as a kanji quiz at the very beginning before subject teaching started. The second test was given when the course was over, after 12 weeks of instruction.

The initial kanji quiz included kanji previously-taught in Levels One and Two, and new kanji to be introduced. The quiz intended to find out how much the CB and NCB speakers knew about the target kanji for the course. The quiz consisted of two parts: A and B (50 questions each), each of which was divided into reading and writing kanji sections (25 questions each). For Part A the twenty-five words (either kanji compound or kanji-kana words) to be tested in each section were chosen randomly from a pool of 376 single kanji (taught in Levels 1 and 2). The twenty-five words to be tested in each section of Part B were selected in the same manner from a pool of not-yet-taught kanji (kanji for Level 3). All kanji words were tested in sentences (not as stand-alone single words) in the quiz.

TABLE 2

CONTENTS OF THE FINAL EXAMINATION

\begin{tabular}{|l|l|l|}
\hline PartA/B & scores & what was tested \\
\hline A & 40 & kanji words reading and writing \\
\hline B-1 & 10 & remembering radicals \\
B-2 & 10 & kanji writing \\
B-3 & 5 & kanji reading and vocabulary knowledge \\
vocabulary knowledge \\
B-4 & 5 & vocabulary knowledge/ kanji recognition \\
B-5 & 10 & radical \\
B-6 & 5 & radical recognition \\
B-7 & 5 & meaning of kanji \\
B-8 & 5 & meaning of kanji, parts of kanji recognition \\
B-9 & 5 & kanji meaning and kanji component recognition \\
B-10 & 5 & key word comprehension \\
B-11 & 10 & N.B> all vocabulary tested above included kanji. \\
B-12 & 10 &
\end{tabular}

The final examination was held around four weeks after the teaching period was over. The examination was basically an achievement test, divided into Parts A and B. Part A had the same format as the kanji quiz at the beginning, and kanji compound or kanji-kana words were chosen randomly in the same manner (40 questions). Thus the cohort performance should provide some indication about how much and to what depth the cohort has learnt the kanji on the list over the twelve week course.

Part B involved 11 different questions, including three questions (B-1, 6, and 7) related to radicals but not directly testing kanji, and a key word comprehension question (B-12) which tested comprehension of lecture content but not kanji directly.

\section{STUdent PERFORMANCE}

To answer the research questions, the test performances by the $\mathrm{CB}$ and $\mathrm{NCB}$ speakers of the cohort were quantitatively examined.

\section{A. Analysis of Student Performance on Quiz}

The participants (36), a mixed cohort of CB (13) and NCB (23) speakers, took a kanji quiz consisting of 100 questions divided into 25 questions for each of:

Part A-reading; Part A-writing (Levels $1 \& 2$ kanji): reading and writing test on already introduced kanji, and

Part B-reading; Part B-writing (Level 3 kanji): reading and writing test on not yet introduced kanji.

The purpose of the quiz was primarily to understand what sort of kanji vocabulary knowledge each speaker group might have before taking the course. The quiz was given to the participants in class and they did it in their own time; however no one took more than 40 minutes. Once the quiz papers were collected and their answers checked, the participants were allowed to take the quiz home and A) correct their answers and B) add new answers if they wished, provided both the original and new answers were clearly shown.

Each part of the quiz was marked twice to find out a) kanji they-thought-they-knew and b) kanji they-actually knew on the list. The first marking was after the in-class test and the second after the participants took the quiz home and selfexamined their answers. The scores for the kanji they-thought-they-knew were generated by giving one mark for any attempted answers, and the scores for the kanji they-actually-knew were generated by giving one mark for correct answers only.

Two markers scored the quiz and any discrepancy in the two markings was corrected by discussion between the two markers.

(A) KANJI THEY-THOUGHT-THEY-KNEW: QUESTIONS THEY RESPONDED TO 
The cohort response averages for reading and writing the taught kanji were nearly $80 \%$, which demonstrates that the learners were reasonably confident with this (Table 3). The CB speaker group (86.8\%: average for reading and $87.4 \%$ for writing) were more confident with the taught kanji but NCB speaker group also showed good confidence ( $75.3 \%$ for reading and $70.1 \%$ for writing). Regarding the kanji never formally introduced to class, the picture was very different. The CB speakers still believed that they knew the kanji reasonably to fairly ( $66.8 \%$ for reading and $48.3 \%$ for writing), whereas the NCB speakers recognised less than a quarter of the kanji at best (26.4\% for reading and $9.9 \%$ for writing).

When we compare the two groups (One-way ANOVA), the rather large $F$ numbers with low $p$-figures (critical value of $F$ for $p=.01$ is 7.44) suggest that the CB and NCB groups definitely differ in perceived knowledge about the new kanji (see Table 4: shadowed columns) and possibly about the taught kanji.

TABLE 3

COMPARISON (1): KANJI THEY- THOUGHT-THEY-KNOW: IN CLASS PERFORMANCE

\begin{tabular}{|l|l|l|l|l|}
\hline Quiz & Whole cohort (39) & CB speakers (13) & NCB speakers (23) \\
\hline A-reading (25) & Taught kanji & $79.4 \%$ & $86.8 \%$ & $75.3 \%$ \\
A-writing (25) & & $76.1 \%$ & $87.4 \%$ & $70.1 \%$ \\
\hline B-reading (25) & Kanji to learn & $41.0 \%$ & $66.8 \%$ & $26.4 \%$ \\
B-writing (25) & & $23.1 \%$ & $48.3 \%$ & $9.9 \%$ \\
\hline
\end{tabular}

TABLE 4

COMPARISON (2): KANJI THEY- THOUGHT-THEY-KNOW: IN CLASS PERFORMANCE



The participants were allowed to take the quiz home to correct or add new answers. 17 participants changed their answers (5 CB and 12 NCB speakers). The summary of answers by participants (Table 5) shows that the take home option increased answer rates for kanji writing more than reading, and particularly writing not-yet-taught kanji (in bold).

TABLE 5

COMPARISON (1): ANSWER RATES AFTER TAKING THE QUIZ HOME

\begin{tabular}{|l|l|l|l|l|l|l|l|}
\hline \multicolumn{9}{|c|}{ Quiz } & \multicolumn{2}{|c|}{ Whole cohort (39) } & \multicolumn{2}{l|}{ CB speakers (13) } & \multicolumn{2}{l|}{ NCB speakers (23) } \\
\hline & & in class & $\begin{array}{l}\text { take home } \\
(17)\end{array}$ & in class & $\begin{array}{l}\text { take home } \\
(5)\end{array}$ & in class & $\begin{array}{l}\text { take home } \\
(12)\end{array}$ \\
\hline A-reading (25) & Taught & $79.4 \%$ & $83.3 \%$ & $86.8 \%$ & $89.5 \%$ & $75.3 \%$ & $79.8 \%$ \\
A-writing (25) & kanji & $76.1 \%$ & $85.9 \%$ & $87.4 \%$ & $91.7 \%$ & $\mathbf{7 0 . 1 \%}$ & $\mathbf{8 2 . 6 \%}$ \\
\hline B-reading (25) & Kanji & $41.0 \%$ & $48.0 \%$ & $66.8 \%$ & $72.3 \%$ & $26.4 \%$ & $34.3 \%$ \\
B-writing (25) & to learn & $23.1 \%$ & $37.6 \%$ & $\mathbf{4 8 . 3 \%}$ & $\mathbf{6 4 . 3 \%}$ & $\mathbf{9 . 9 \%}$ & $\mathbf{2 2 . 4 \%}$ \\
\hline
\end{tabular}

\section{(B) KANJI THE PARTICIPANTS REMEMBER CORRECTLY}

The participants' answers in the quiz were then examined for correct answers. Table 6 shows the summary of the cohort/group scores for 1) answered in class; 2) increased answer rate after taking home; 3) correct answers in class; and 4) correct answers after self-check.

Taking the quiz home provided both groups with an opportunity to increase their answer rate noticeably (about $10 \%$ or more: e.g. A-writing: whole cohort: from $76.1 \%$ to $85.9 \%$, NCB group: from $70.1 \%$ to $82.6 \%$; B-writing: CB group: from $48.3 \%$ to $64.3 \%$ ) (refer to Table 5 or Table 6 columns (1) Answered in class and (2) Answer rate after taking home). However, there was little difference between (3) correct answers in class and (4) correct answers after self-check.

The CB and NCB groups were compared in terms of how correctly they remembered the kanji reading and writing in the quiz. The internal consistency of the four quiz sections was reasonable (Cronbach's $\alpha=.855$ ). Within each group in this study, kanji performance variance was reasonably homogeneous except for B-writing section (the-not-yet-taught) (see Table 7). 
TABLE 6

COMPARISON (1): PARTICIPANTS' ANSWERS IN KANJI QUIZ

\begin{tabular}{|l|l|l|l|l|l|}
\hline & & $\begin{array}{l}\text { Answered in } \\
\text { class }(\mathbf{\%}) \\
(\mathbf{1})\end{array}$ & $\begin{array}{l}\text { Answer rate after } \\
\text { taking home (\%) } \\
(\mathbf{2})\end{array}$ & $\begin{array}{l}\text { Correctly answered } \\
\text { in class (\%) } \\
(\mathbf{3})\end{array}$ & $\begin{array}{l}\text { Correct answers after } \\
\text { taking home (\%) } \\
(\mathbf{4})\end{array}$ \\
\hline A-reading & Whole cohort & 79.4 & 83.3 & 63.4 & 63.7 \\
& CB-group & 86.8 & 89.5 & 68.6 & 68.9 \\
& NCB-group & 75.3 & 79.8 & 60.5 & 60.7 \\
\hline A-writing & Whole cohort & 76.1 & $\mathbf{8 5 . 9}$ & 66.4 & 47.3 \\
& CB-group & 87.4 & 91.7 & 60.6 & 61.8 \\
& NCB-group & 70.1 & $\mathbf{8 2 . 6}$ & 28.4 & 39.1 \\
\hline B-reading & Whole cohort & 41.0 & 48.0 & 42.5 & 25.8 \\
& CB-group & 66.8 & 72.3 & 16.2 & 42.5 \\
& NCB-group & 26.4 & 34.3 & 12.8 & 16.3 \\
\hline B-writing & Whole cohort & 23.1 & $\mathbf{3 7 . 6}$ & 27.7 & 13.1 \\
& CB-group & 48.3 & $\mathbf{6 4 . 3}$ & 4.3 & 27.7 \\
& NCB-group & 9.9 & $\mathbf{2 2 . 4}$ & 4.9 \\
\hline
\end{tabular}

TABLE 7

HOMOGENEITY OF VARIANCES WITHIN EACH GROUP

\begin{tabular}{|l|l|l|l|l|}
\multicolumn{5}{c|}{ HOMOGENEITY OF VARIANCES WITHIN EACH GROUP } \\
\hline A-reading & Levene Statistics & df1 & df2 & Sig. \\
A-writing & .002 & 1 & 34 & .968 \\
B-reading & .283 & 1 & 34 & .599 \\
B-writing & .022 & 1 & 34 & .883 \\
\hline
\end{tabular}

The correctly answered kanji ratios were definitely different between the CB and NCB speaker groups for three of the sections: previously-taught kanji writing, not-yet-taught kanji reading and writing $(F>7.44$ : Table 8$)$. Mean test revealed that the kanji performance scores in the quiz were not associated with the independent variable (CB or NCB) for the taught kanji reading (Eta value $.259<0.5$ ). However they may or may not be associated with whether participants belonged to CB or NCB groups (Eta value around .5) for the other three sections: taught kanji writing, notyet-taught kanji reading and writing (Table 9: next page).

TABLE 8

COMPARISON: PARTICIPANTS’ CORRECT ANSWERS IN KANJI QUIZ (ANOVA)

\begin{tabular}{|l|l|l|l|l|}
\hline & & df & $F$ & Sig \\
\hline A-reading & Between CB and NCB Groups & 1 & 2.438 & .128 \\
A-writing & Between CB and NCB Groups & 1 & 13.213 & .001 \\
B-reading & Between CB and NCB Groups & 1 & 11.441 & .002 \\
B-writing & Between CB and NCB Groups & 1 & 14.964 & .000 \\
\hline
\end{tabular}

TABLE 9

MEASURES OF ASSOCIATION BETWEEN GROUP IDENTITY AND PERFORMANCE

\begin{tabular}{|l|l|l|}
\hline & Eta & Eta Squared \\
\hline A-reading * $\mathrm{CB}=1, \mathrm{NCB}=0$ & .259 & .067 \\
A-writing * $\mathrm{CB}=1, \mathrm{NCB}=0$ & .529 & .280 \\
B-reading * $\mathrm{CB}=1, \mathrm{NCB}=0$ & .502 & .252 \\
$\mathrm{~B}-$-writing $* \mathrm{CB}=1, \mathrm{NCB}=0$ & .553 & .306 \\
\hline
\end{tabular}

\section{B. Student Performance in the Final Examination}

Part A was in the same format as the kanji quiz and questions were constructed in the same manner from the same pool of single kanji. Part B consisted of questions testing kanji words (with a focus on kanji learning strategies that were introduced and practised through the previous twelve weeks).

The participants' scores for the final examination were quantified and grouped as follows: 1) Part A: kanji reading and writing in text, and 2) Parts B-2, B-3, B-4, B-5, B-8, B-9, B-10, and B-11: questions testing kanji words (refer back to Table 2 for details). As seen in Table 10, the CB speaker group outperformed the NCB speaker group in both Parts A and B. The internal consistency of 1) and 2) was good (Cronbach's $\alpha=.907)$, and the correlation between the cohort performance in Parts A and B was $(r h o=.883, \mathrm{p}=.000)$.

TABLE 10

COMPARISON: PARTICIPANTS' CORRECT ANSWERS IN FINAL EXAMINATION

\begin{tabular}{|l|l|l|l|l|}
\hline & & Whole cohort (36) & CB group (13) & NCB group (23) \\
\hline Part A & Mean & $26.24(65.6 \%)$ & $32.69(81.7 \%)$ & $22.59(56.5 \%)$ \\
(out of 40) & Std Dev & 7.96 & 4.14 & 7.27 \\
\hline Part B & Mean & $39.19(65.3 \%)$ & $49.65(82.8 \%)$ & $33.28(55.5 \%)$ \\
(out of 60) & Std Dev & 11.40 & 6.94 & 8.89 \\
\hline
\end{tabular}

Lastly when the participants' kanji performance in the quiz and final examination were placed together, the gap between the CB and NCB speaker groups became more distinct (Table 11). All $F$ figures became larger (critical $F$ 
figure was 7.44) and significance levels became statistically significant. In particular $F$ figures for the final examination were larger than those in the quiz. Eta values for Part A and B were .618 and .700 respectively and showed even stronger connection between the scores and group identity than in the quiz.

TABLE 11

COMPARISON: PARTICIPANTS' COMBINED KANJI PERFORMANCE (ANOVA)

\begin{tabular}{|l|l|l|l|l|l|}
\hline & & & $\mathrm{df}$ & $F$ & Sig \\
\hline Final & Part A & Between CB and NCB Groups (combined) & 1 & 21.063 & .000 \\
Examination & Part B & Between CB and NCB Groups (combined) & 1 & 32.660 & .000 \\
\hline Kanji Quiz & A-reading & Between CB and NCB Groups (combined) & 1 & 3.814 & .056 \\
& A-writing & Between CB and NCB Groups (combined) & 1 & 15.500 & .000 \\
& B-reading & Between CB and NCB Groups (combined) & 1 & 11.872 & .002 \\
& B-writing & Between CB and NCB Groups (combined) & 1 & 15.941 & .000 \\
\hline
\end{tabular}

\section{DISCUSSION}

This study was conducted in a pilot course which aimed to assist both CB and NCB speakers with their Japanese learning, with a particular focus on kanji learning and subsequent vocabulary building. 13 CB and 23 NCB speakers participated in this study. At the beginning of the course, they were given a quiz of 100 kanji word questions in class without any advance notice. For the following 12 weeks, the participants attended lectures where kanji were presented formally as a part of the Japanese writing system, and tutorials in which they practised methods/strategies to learn kanji systematically (refer back to Table 1). The participants also conducted independent kanji learning projects for those 12 weeks. Then they were given another kanji test as part of the final examination - Part A: a smaller test (40 questions) made in the same way as the quiz at the beginning and Part B: kanji questions requiring methods/strategies practiced in the tutorials (see 3.3. Methods).

The study was conducted to answer three questions (see 3.2 The purpose of the study). The first question asks how well CB learners adjusted to kanji learning compared to NCB learners in the same level Japanese language class.

The scores from the quiz at the beginning were examined at two levels: 1) kanji participants thought they knew about and 2) kanji they remembered correctly. The former included kanji which they were very confident they knew to those they recollected well enough to produce answers (they thought their answers might be right).

Comparison of CB and NCB speaker groups at the first level showed that the CB and NCB groups definitely have different perceived knowledge regarding the new kanji in class and possibly about previously-taught kanji. The low scores by the NCB group for not-yet-taught kanji (Part B: reading 26.4\% and writing 9.9\%) strongly indicated that NCB speakers have little idea about kanji which have not been formally introduced to them. On the other hand, the CB speakers believed that they knew not-yet-taught kanji to a certain extent (Part B: reading 66.8\% and writing 48.3\%). The gaps between the scores for reading and writing not-yet-taught kanji might indicate writing is harder than reading kanji for the both groups when it comes to unfamiliar kanji. However, it should be noted that the scores by the NCB speaker group were not much lower regarding previously-taught kanji (Part A-reading and writing: CB 86.8\% and $87.4 \%$ and NCB $75.3 \%$ and $70.1 \%$ ).

Statistical analysis demonstrated the two groups can be similar with reading of previously-taught kanji $(F<$ the critical value; $p=0.01$ ) in terms of responsiveness and possibly so for writing previously-taught kanji. It is also interesting that the CB speaker group answered slightly more to kanji writing questions whereas the NCB speaker group answered more to the reading questions.

When it comes to the correctness of the kanji they remembered, Mean test results suggest that participants' performance for reading previously-taught kanji was not affected by being a CB or NCB speaker. However their performance for reading not-yet-taught kanji and writing kanji (both previously-taught and not-yet-taught) may or may not relate to which group they belonged to. In addition, variance within each group was reasonably homogeneous except for not-yet-taught kanji writing. Therefore it can be said that the CB and NCB speakers can have similar facility with reading kanji which have been formally introduced (i.e, their meaning, pronunciation/reading and orthography). In other words, the more they work on learning kanji, the better they can read them regardless of a character or noncharacter based background. However, CB speakers will likely outperform NCB speakers in writing kanji, even if the NCB speakers work equally hard on the previously-taught kanji.

The study's second research question asks what each group's test performance was at the beginning and end of the course.

The comparison of the participant group performances in the two tests (Table 6, Column 3 and Table 10) suggested some improvement for both groups. The CB speaker group raised their kanji performance in the examination by scoring $81.8 \%$ for remembering kanji (Part A: Table 10), which is higher than their group scores for any sections in the quiz (Table 6, Column 3). The CB speaker group did even better with using learnt strategies to recognise both single and compound kanji (Part B: Table 10). The NCB speaker group managed to remember 56.5\% of kanji correctly in the final examination (Part A: Table 10), which was slightly lower than their previous score for previously-taught kanji reading, but remarkably higher than the scores for the remaining three sections, i.e., not-yet-taught kanji reading and writing and previously-taught kanji writing. 
The two test combined statistical analysis (Table 11) revealed that the CB and NCB speaker groups in this study differed in their kanji learning, except for reading of previously-taught kanji ( $F>$ critical figure), and that this will very likely be the case for each class we might have in the future $(p \leq .002)$.

The third and final research question asks what are the possible fundamental differences in kanji learning between the NC and NCB groups.

The large discrepancy between the $\mathrm{CB}$ and NCB speaker groups' responses to new kanji suggests that having a character background assists the CB learners at the initial stage of kanji learning. The CB learners not only already know single characters but also the writing system (and system rules), and have had character learning experience in their mother tongue.

When new kanji are introduced into a lesson, CB speakers can sometimes identify the kanji by sight, even without knowing the meaning or pronunciation. Firstly, they can recognise the word without going through analysis of strokes, radicals, or (single character) morphemes (refer to Figure 1 in 2.1). Secondly, they know how to assign meaning to the kanji from their character learning experience, and can develop abstract units (lemmas: Levelt, 1989) by accumulating form-meaning information.

On the other hand, without a character network in their cognition, NCB speakers have no idea about newly presented kanji unless they have seen similar kanji before (e.g., analogous shape, components or context). Their word recognition training with alphabetic languages is not easily adapted to their kanji learning (Taft, Liu \& Zhu, 1999). This two-fold unfamiliarity might cause considerable anxiety as well as difficulty for NCB speakers.

In terms of the correctness of the kanji the participants remembered, in both groups a recognizable proportion of their answers in the quiz were either simply wrong or incomplete (compare the rates between Column (2) and (3) in Table 6). Very interestingly, the corrections and additions after taking the quiz home did not much improve the correctness of either kanji reading or writing (compare Column (3) and (4) in Table 6).

This indicates self-correction of kanji (which have been learnt partially or remembered wrongly) might be very hard, regardless of whether the learner is a $\mathrm{CB}$ or NCB speaker. A possible explanation is that the CB learners might have strong interference from their L1. The NCB speakers might not have enough information in lemmas to reach a threshold to activate a link between appropriate orthographic representation and semantic or phonological elements.

The kanji performance of both groups (particularly the CB speakers) appears to have improved after completing the lectures and tutorials, and conducting their own kanji learning project. The validity or reliability of two tests has not been confirmed yet, and it is not certain to what extent the knowledge introduced in the course was utilised by the participants. No measurement of each participant's time and effort though the semester was available, so in this study the improvement cannot be reliably connected to any particular factor(s).

However, at least it may be said that both groups can improve their kanji learning by increasing exposure to kanji. The difference between the two groups became more distinct when the two test results were combined (Table 11). This suggests that the gap between the two groups may become larger when they are given the same instruction and opportunities for kanji learning. In other words, NCB speakers require more assistance, resources or time to catch up with CB speakers in class.

\section{CONCLUSIONS}

The findings of the analysis can be summarised around the research questions as follows.

Before taking the course, CB speakers as a group performed better overall on both previously-taught and not-yettaught kanji, in terms of both recognition and correctness. The difference between the groups could likely be attributed to whether they were $\mathrm{CB}$ or NCB speakers, except for reading previously-taught kanji.

When the CB and NCB speaker groups' test performance was examined at the end of the course, the difference observed at the beginning appeared to intensify. Even though both groups improved their performance noticeably, the improvement made by the CB speaker group was greater.

The findings provide support for the argument that a character based background is overall beneficial for kanji learning. However, the findings that there is little difference between the groups in reading previously-taught kanji and the poor rates of self-correction need to be explored further to understand kanji learning by both learner groups.

\section{REFERENCES}

[1] Ingulsrud, J.E., \& Allen, K. (1999). Learning to read in China - Sociolinguistic perspectives on the acquisition of literacy. Lewiston, NY: The Edwin Mellen Press.

[2] Levelt, W. J. M. (1989). Speaking form intention to articulation. Cambridge, MA: MIT Press. (quoted in Taft, Liu \& Zhu, 1999).

[3] McClelland, J.L., \& Rumelhart, D. E. (1981). An interactive activation model of context effects in letter perception, part 1: An account of basic findings. Psychological Review, 88, 375-407.

[4] Sato, K. (1989). Kanji and issues surrounding the national language, Kanji Course Vol. 11. Tokyo: Meiji-shoin.

[5] Taft, M, Liu, Y., \& Zhu, X. (1999). Morphemic processing in reading Chinese. In J. Wong, A.W. Inhoff \& H. Chen (eds.), Reading Chinese Script: A cognitive analysis, Chapter 5, 91-113. Mahwah, NY: Lawrence Erlbaum Associates.

[6] Tamaoka, K. (1991). Psycholinguistic nature of the Japanese orthography. Studies in Language and Literature 11. 1, 49-82. 
[7] Zhou, X., Shu, H., Bi, Y., \& Shi, D. (1999). Is there phonologically mediated access to lexical semantics in reading Chinese? In J. Wong, A.W. Inhoff \& H. Chen (eds.), Reading Chinese Script: A cognitive analysis, Chapter 7, 135-171. Mahwah, NY: Lawrence Erlbaum Associates.

Sayuki Machida, Dr is a Senior Lecturer at the Asia Institute, The University of Melbourne. Her research interest lies in Second Language acquisition and Language and Culture. Her publication encompasses test anxiety, interlanguage development, reading comprehension, and teaching methodologies in SL. Current research includes text comprehension, translation, and kanji learning. 